\title{
Using bilateral internal thoracic arteries-just do it
}

\author{
Saswata Deb, MD, BSc, and Stephen E. Fremes, MD, MSc, BSc
}

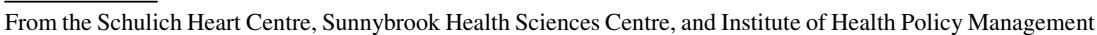
and Evaluation, University of Toronto, Toronto, Ontario, Canada.

Disclosures: Authors have nothing to disclose with regard to commercial support.

Received for publication March 18, 2016; accepted for publication March 18, 2016; available ahead of print April $23,2016$.

Address for reprints: Stephen E. Fremes, MD, MSc, BSc, Schulich Heart Centre, Sunnybrook Health Sciences Centre, University of Toronto, 2075 Bayview Ave, Room H405, Toronto, ON, Canada M4N 3M5 (E-mail: stephen.fremes@sunnybrook.ca).

J Thorac Cardiovasc Surg 2016;152:128-30

$0022-5223 / \$ 36.00$

Copyright (c) 2016 by The American Association for Thoracic Surgery

http://dx.doi.org/10.1016/j.jtcvs.2016.03.026
}

Conventional coronary artery bypass grafting surgery (CABG) is commonly performed using a left internal thoracic artery (LITA) to bypass the left anterior descending (LAD) territory and saphenous vein grafting to bypass other non-LAD territories; however, there has been a surge of enthusiasm for a multiarterial grafting strategy $^{1-3}$ in general, and bilateral internal thoracic arteries (BITAs) in particular. $^{4-6}$ The importance of arterial grafting, including BITA, is strongly supported by society guidelines $^{7}$ (eg, Society of Thoracic Surgeons, ${ }^{8}$ American College of Cardiology/American Heart Association, ${ }^{9}$ and European Society of Cardiology and the European Association for Cardio-Thoracic Surgery ${ }^{10}$ ). Despite these recommendations, only $5 \%$ of isolated CABG procedures engage a BITA grafting approach. ${ }^{11}$ Potential reasons for lack of BITA use by cardiac surgeons include increased operative time, greater technical challenge, potential for sternal wound complications, and the lack of perceived survival benefit until the second postoperative decade. ${ }^{11,12}$ Furthermore, optimal graft configuration in patients undergoing multiarterial revascularization is unclear. ${ }^{4}$ Important questions include whether both internal thoracic arteries (ITAs) should be directed to the left coronary system, whether the LITA should always be directed to the LAD, and the appropriateness of in situ versus free conduit (typically for the right ITA [RITA]).

To this end, Magruder and colleagues ${ }^{13}$ undertook a single-center, retrospective study investigating whether BITA graft configuration affects long-term clinical outcomes. More specifically this study included 762 patients who underwent isolated CABG between 1997 and 2014 using a BITA strategy stratified into 4 relevant groups: in situ LITA to LAD and in situ RITA to the left coronary circulation ( $\mathrm{n}=239$ ), in situ LITA-LAD and in situ RITA to right coronary circulation $(\mathrm{n}=239)$, in situ RITA-LAD and in situ LITA to left coronary circulation $(\mathrm{n}=185)$, and in situ LITA-LAD and free-composite RITA to any part of the coronary circulation $(n=99)$. Using these 4 basic configurations, the authors then tested 3 grafting hypotheses

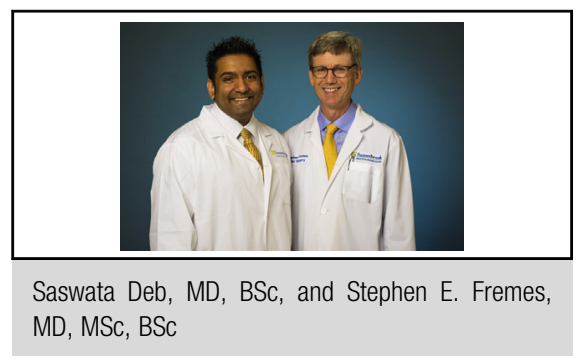

\begin{abstract}
Central Message
Magruder and colleagues evaluated clinical outcomes between different configurations of bilateral internal thoracic arteries in patients undergoing isolated coronary artery bypass grafting surgery. This article highlights the importance of that work, along with its strengths and weaknesses.
\end{abstract}

See Article page 120 using propensity scores to adjust for baseline differences. With a median follow-up of 1128 days, they concluded that graft configuration was not an independent predictor of repeat revascularization or death. Specifically, adjusted hazard ratios for death, repeat revascularization, and composite of death and repeat revascularization were similar between the 2 in situ BITA grafting strategies for the left coronary circulation and comparing an in situ LITA-LAD versus an in situ RITA-LAD. Lastly, in patients with a LITA-LAD configuration, adjusted outcomes were similar in patients with RITA grafting (in situ or Y) to the left coronary versus the right coronary system.

There are a number of key points that are worth discussing. It is known that degree of target vessel stenosis and competitive flow has been shown to influence ITA patency. ${ }^{14}$ In this study, although BITA grafting was avoided in patients with diabetes, obesity, and/or pulmonary disease, it was generally left to the surgeon's discretion for choosing the graft configuration and it is not known what target vessel characteristics and anatomic criteria were used. Furthermore, each group had on average 3 distal anastomoses, suggesting there was at least a third conduit (with the exception of the composite group); thus, whether clinical outcomes were influenced by the non-ITA conduits is not known.

In adjusted analyses using propensity scores, none of the comparisons were statistically different. According to Kaplan-Meier curves presented in the article, ${ }^{13}$ the composite outcome of repeat revascularization and death showed 
statistical differences. Presumably baseline differences account for this inconsistency and not the grafting strategy per se. It looks like the composite group did worse overall. Although this may have been influenced by follow-up issues, the composite group had more prevalence of diabetes and required more intraoperative transfusions. With regard to composite or free RITA configurations, a randomized trial by Nasso and colleagues ${ }^{15}$ showed that event-free survival was similar between patients receiving composite RITA (off the LITA) versus free RITA. In addition, a recent study by Robinson and colleagues ${ }^{16}$ comparing BITA Y grafting (using a free RITA) showed that at a mean of 5.5 years post-CABG angiography, degree of native vessel stenosis (odds ratio, 0.66 per $10 \%$ increase), and anatomic territory (circumflex odds ratio, 2.64 and right coronary artery odds ratio, 6.73 vs anterior territory) were among the predictors of anastomotic occlusion. In the study by Magruder and colleagues, ${ }^{13}$ majority of the composite RITA grafts went to the obtuse marginal and perhaps this was done based on certain anatomic factors that were not captured in the study.

Magruder and colleagues ${ }^{13}$ showed that there was no difference in adjusted outcomes between RITA targeted to the left versus the right coronary system. It is known that the right coronary artery is larger and therefore native competitive flow is a problem. It has been shown that saphenous vein grafts have better patency compared with ITA grafts at $<5$ years for moderate right coronary artery stenosis $(>70 \%)$; however, late after surgery, ITA are more effective. ${ }^{17}$ Furthermore, Sabik and colleagues ${ }^{18}$ showed that at 9.2 years of follow-up, late survival was similar between patients receiving a second ITA to the circumflex versus the right coronary system. As such it is reassuring that longterm outcomes between ITA to the right versus left were comparable. Given that median follow-up was 1128 days (3.09 years), 5- and especially 10-year estimates should be made with caution. In addition, it is important to emphasize that the RITA was used preferentially for the left coronary system overall.

Finally, Magruder and colleagues ${ }^{13}$ conducted an observational study, with small numbers and few events, limited follow-up, and temporal biases in the treatment strategies. The investigators appropriately computed post hoc power studies that suggested the study was only powered to test for relatively large between-group differences. One could argue that such differences are not biologically plausible considering the magnitude of effect of a second arterial graft compared with a single arterial graft; also, smaller differences that may still be clinically important would not be evident. The patients included in the study were highly selected (ie, young and healthy), which impedes external validity. Furthermore, BITA was avoided in patients with diabetes in this study, at least in the earlier years. Diabetes is a common reason for many surgeons to exclude the use of
BITA grafting in efforts to decrease risk of sternal wound infection. ${ }^{19}$ However, Raza and colleagues ${ }^{2}$ performed a large study of 11,922 patients with diabetes and concluded that BITA grafting maximizes long-term survival and recommended use in all patients with diabetes with low risk of deep sternal wound infection. Furthermore, a large portion of ITAs were harvested in a skeletonized fashion and skeletonization has also been shown to be safe in diabetic patients undergoing BITA harvesting. ${ }^{20}$

Overall, Magruder and colleagues ${ }^{13}$ should be congratulated for undertaking this retrospective study and applying meticulous analytic methods to compare long-term outcomes. Given that the survival advantage typically becomes apparent during the second decade after BITA surgery, ${ }^{11}$ long-term studies such as this-along with the much anticipated late results of the Arterial Revascularization Trial $^{21}$ that compares BITA to single ITA-will hopefully redefine conventional practices of $\mathrm{CABG}$ with respect to conduit selection. What does this particular study add? Point estimates for the adjusted hazard ratio of death or repeat revascularization were close to unity for each of the primary grafting hypothesis comparisons. The takehome message is that using BITAs is more important than the precise configuration of the BITAs used. In other words: BITA—just do it!

\section{References}

1. Deb S, Singh SK, Moussa F, Tsubota H, Une D, Kiss A, et al. The long-term impact of diabetes on graft patency after coronary artery bypass grafting surgery: a substudy of the multicenter Radial Artery Patency Study. J Thorac Cardiovasc Surg. 2014;148:1246-53; discussion 53.

2. Raza S, Sabik JF III, Masabni K, Ainkaran P, Lytle BW, Blackstone EH. Surgical revascularization techniques that minimize surgical risk and maximize late survival after coronary artery bypass grafting in patients with diabetes mellitus. $J$ Thorac Cardiovasc Surg. 2014;148:1257-64; discussion 64-6.

3. Buxton BF, Shi WY, Tatoulis J, Fuller JA, Rosalion A, Hayward PA. Total arterial revascularization with internal thoracic and radial artery grafts in triple-vessel coronary artery disease is associated with improved survival. J Thorac Cardiovasc Surg. 2014;148:1238-43; discussion 43-4.

4. Shi WY, Hayward PA, Tatoulis J, Rosalion A, Newcomb AE, Fuller JA, et al. Are all forms of total arterial revascularization equal? A comparison of single versus bilateral internal thoracic artery grafting strategies. J Thorac Cardiovasc Surg. 2015;150:1526-33. 34.e1-3; discussion 33-4.

5. Kajimoto K, Yamamoto T, Amano A. Coronary artery bypass revascularization using bilateral internal thoracic arteries in diabetic patients: a systematic review and meta-analysis. Ann Thorac Surg. 2015;99:1097-104.

6. Takagi H, Goto SN, Watanabe T, Mizuno Y, Kawai N, Umemoto T. A metaanalysis of adjusted hazard ratios from 20 observational studies of bilateral versus single internal thoracic artery coronary artery bypass grafting. $J$ Thorac Cardiovasc Surg. 2014;148:1282-90.

7. Kolh P, Kurlansky P, Cremer J, Lawton JS, Matthias S, Fremes S. Transatlantic editorial: a comparison between European and North American guidelines on myocardial revascularization. Eur J Cardiothorac Surg. 2016;49:1307-17.

8. Aldea GS, Bakaeen F, Pal J, Fremes S, Head SJ, Sabik J, et al. The Society of Thoracic Surgeons Clinical Practice Guidelines on Arterial Conduits for Coronary Artery Bypass Grafting. Ann Thorac Surg. 2016;101:801-9.

9. Hillis LD, Smith PK, Anderson JL, Bittl JA, Bridges CR, Byrne JG, et al. 2011 ACCF/AHA Guideline for Coronary Artery Bypass Graft Surgery. A report of the American College of Cardiology Foundation/American Heart Association Task Force on Practice Guidelines. Developed in collaboration with The American Association for Thoracic Surgery, Society of Cardiovascular Anesthesiologists, and Society of Thoracic Surgeons. J Am Coll Cardiol. 2011;58:e123-210. 
10. Windecker S, Kolh P, Alfonso F, Collet JP, Cremer J, Falk V, et al. 2014 ESC/EACTS Guidelines on myocardial revascularization: the Task Force on Myocardial Revascularization of the European Society of Cardiology (ESC) and the European Association for Cardio-Thoracic Surgery (EACTS) developed with the special contribution of the European Association of Percutaneous Cardiovascular Interventions (EAPCI). Eur Heart J. 2014;35: 2541-619.

11. Puskas JD, Lazar HL, Mack MJ, Sabik JF III, Paul Taggart D. State-of-the-art coronary artery bypass graft. Semin Thorac Cardiovasc Surg. 2014;26:76-94.

12. Umakanthan J, Jeyakumar P, Umakanthan B, Jeyakumar N, Senthilkumar N, Saraswathy MR, et al. Barriers to the universal adoption of bilateral internal mammary artery grafting. Int J Surg. 2015;16:179-82.

13. Magruder JT, Young A, Grimm JC, Conte JV, Shah AS, Mandal K, et al. Bilateral internal thoracic artery grafting: does graft configuration affect outcome? J Thorac Cardiovasc Surg. 2016;152:120-7.

14. Sabik JF III, Lytle BW, Blackstone EH, Khan M, Houghtaling PL, Cosgrove DM. Does competitive flow reduce internal thoracic artery graft patency? Ann Thorac Surg. 2003; 76:1490-6; discussion 7.

15. Nasso G, Coppola R, Bonifazi R, Piancone F, Bozzetti G, Speziale G. Arterial revascularization in primary coronary artery bypass grafting: direct comparison of 4 strategies—results of the Stand-in-Y Mammary Study. J Thorac Cardiovasc Surg. 2009; 137:1093-100.

16. Robinson BM, Paterson HS, Naidoo R, Dhurandhar V, Denniss AR. Bilateral internal thoracic artery composite Y grafts: analysis of 464 angiograms in 296 patients. Ann Thorac Surg. 2016;101:974-80.

17. Sabik JF III, Blackstone EH. Coronary artery bypass graft patency and competitive flow. J Am Coll Cardiol. 2008;51:126-8.

18. Sabik JF III, Stockins A, Nowicki ER, Blackstone EH, Houghtaling PL, Lytle BW, et al. Does location of the second internal thoracic artery graft influence outcome of coronary artery bypass grafting? Circulation. 2008;118(Suppl):S210-5.

19. Hemo E, Mohr R, Uretzky G, Katz G, Popovits N, Pevni D, et al. Long-term outcomes of patients with diabetes receiving bilateral internal thoracic artery grafts. J Thorac Cardiovasc Surg. 2013;146:586-92.

20. Hirose H, Amano A, Takanashi S, Takahashi A. Skeletonized bilateral internal mammary artery grafting for patients with diabetes. Interact Cardiovasc Thorac Surg. 2003;2:287-92.

21. Taggart DP, Lees B, Gray A, Altman DG, Flather M, Channon K. Protocol for the Arterial Revascularisation Trial (ART). A randomised trial to compare survival following bilateral versus single internal mammary grafting in coronary revascularisation. Trials. 2006;7:7. 